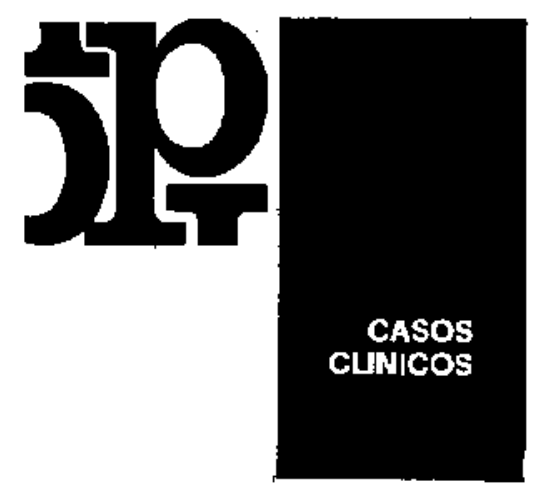

DR, SERGIO BORLONE ROJAS *.

\title{
Estenosis Hipertrófica del Píloro familiar
}

Intróducción. La Estenosis Hipertrófica del Píloro (EHP) es una afección específica de la tercera a cuarta semana de la vida que se diagnosticit con cierta facilidad y se encuentra anualmente con no rara frecuencia.

Aunque la etiología de la EHP es desconocida, existen factores genéticos claros que se describen cada vez con mayor frecuencia (4).

El propósito de esta comunicación es presentar el caso de una familia de Coquimbo, Chile, cuyos tres hijos vivos presentaron el cuadro clásico de la EHP. (6) (9) (10).

No se ha encontrade en la literatura médica nacional otros casos semejantes publicados.

Casuística. Caso clínico Nọ 1: J.E.P.R. (Observación No 63.105):

Segundo hijo varón. Nació cl 6 de Febrero de 1969. Embarazo normal no sontrolado. Parto de término en nalgas con retención de cabeza última. Apgar con score al ler, minuto de 9. Pesó 3.150 con $50 \mathrm{~cm}$. de tallí. Lactancia natural. Desde los 17 días de edad presenta vómitos frecuentes, post-prandiales precoces, explosivos $y$ constipación. Llanto de hambre permanente y baja de peso. Consultó en tres oportunidades antes de precisar el diagnóstico de EHP. A1 ingreso hay deshidratación moderada, ondàs peristálticas gástricas notorias y es dudosa la palpación de la oliva pilórica. El estudio radiológico revela signos claros de dilatación gástrica y píloro clongado. La operación de C. Ramdstedt se efectuó ef 11 de Marzo de 1969. El post-operatorio sólo fue complicado de una diarrett con deshidratación intrahospitalaria grave que prolongó la estadía. Control

\footnotetext{
"Scrvicio de Pediatria. Hospilal "San Pablo" de Cuquinebo, chile.
}

actual a los 4 años de edad revela a un niño sano con $14 \mathrm{~kg}$. de peso.

Caso clínico No 2. P.A.P.R. (Observación No 69.776$)$ :

Tetcer hijo varón nacido el 8 de agosto de 1970 producto de un embarazo y parto normales. Pesó 3.250 gr. y midió $50 \mathrm{~cm}$. Se alimentó a pecho. Desce los 14 días de vida tiene vómitos continuados y proguesjvos en proyectil. Consulta dos veces antes de confirmar el diagnóstico de EHP. A su ingreso está deshidratado moderadamente y enflaquecido, ondas peristálticas y tumor pilórico palpable. El examen radiologico confirma una EHP. El $1^{\circ}$ de Septiembre de 1970 se efectuó la piloromiotomía clásicn. Presentó vómitos post-operatorios las primeras $48 \mathrm{hrs}$., y es dado de alta en buenas condiciones. Controlado a los 2 años 6 meses está sano y con peso de 12 kilogramos.

Caso clínico Nọ 3, J.P.P.R., (Observación 81.199):

Cuarto hijo, única mujer, nacida cl 22 de Septiembre de 1972. Embarazo y parto normales. Peso 3.300 gr. y $49 \mathrm{~cm}$. de talla. Se alimentó con pecho materno hasta su enfermedad. A los 18 días conienza con vómitos violentos pero aislados por lo cual consulta de inmediato en cl Policlínico de Pediatría. Se constata una niña de buena vitalidad, hambrienta, sin deshidratación, ondas peristálticas y oliva pilórica palpable. No se efcctuó estudio radiológico. Se operó el 16 de octubre de 1972. Post-operatorio normal. Se controla a los 8 meses de edad totalmente sana con peso de $7 \mathrm{~kg}$.

Comentario. Un teporte como el presentado es excepcional por su rareza. En la revisión de Cameron (3) en 1954 se describen 8 casos de 
TABLA No 1

RESUMEN CLINICO DE LOS HERMANOS P. R., COQUIMBO. CHILE (I973)

\begin{tabular}{llll}
\hline Nombre & JEPR & PAPR & JPPR \\
\hline Peso de nacimiento & 3150 & 3250 & 3300 \\
Peso de ingreso & 3000 & 3000 & 3100 \\
Comienzo de vómitos & $17 \mathrm{ds}$. & $14 \mathrm{ds}$. & $18 \mathrm{ds}$. \\
Duración de vómitos & $4 \mathrm{ds}$. & $6 \mathrm{ds}$. & $1 \mathrm{~d}$. \\
Consultas previas & 3 & 2 & 0 \\
Ondas peristáiticas & ++ & +++ & ++ \\
Oliva pilórica & Dudosa & Palpable & Palpable \\
Deshidratación & Moderada ModeradaMuy leve \\
Radiología & Típica & Típica & No se efectuó \\
Piloromiotomía & $11-3-69$ & $19-9-70$ & $16-9-72$ \\
Complicaciones & No & No & No \\
Control actual & 4 años & 2 a 8 m. 8 meses \\
& Sano & Sano & Sano \\
\hline
\end{tabular}

T ABLA No $2\left(^{*}\right)$

CASOS DE TRES HERMANOS DE UNA FAMLLA CON EHP.

\begin{tabular}{lllll}
\hline Autor & $\begin{array}{l}\text { Nacionalidad } \\
\text { del autor }\end{array}$ & Fecha & Sexo(*) & $\begin{array}{c}\text { Número } \\
\text { del hijo } \\
\text { con EHP }\end{array}$ \\
\hline Parker & USA & 1927 & ? ? ? & $2-3-4$ \\
Mac-Gregor Canadá & 1931 & H H ? & 457 \\
Halbertsman Alemania & 1936 & H M H & 124 \\
Donovan & USA & 1938 & H H H & 159 \\
Ruddock & USA & 1944 & H H M & $? ?$ ? \\
Cathala & Francia & 1944 & M M M & $? ? ?$ \\
Adlington & Inglatera & 1949 & H H H & 123 \\
Nafe & USA & 1954 & H H H & 123 \\
\hline
\end{tabular}

(*) Original de A. L. Cameron,

$\mathbf{H}=$ Hombre $\mathbf{M}=$ Mujer.

grupos familiares semejantes al descrito por nosotros. En 1902 se sugiere por primera vez und relación de tipo familiar en la EHP. En 1912 el propio C. Ramstedt (3) informa de dos hermanos con EHP, a uno le practicó por primera vez su operación. El otro niño no operado fallece días después y en la autopsia se constata el tumor pilórico. En Estados Unidos el primer caso de tres hermanos afectados por la EHP datan de una publicación de Parker en 1927. (Tabla No 2). Se han descrito casos de 4 hermanos afectados en dos ocasiones. (3). Se relata incluso que Cornelia de Lange habría comunicado un grupo de 5 bermanos en 1936 (3).

La frecuencia de la EHP en la población varía según el grupo étnico y región geográfica (11). (Tablas No 3 y No 4). En general la frecuencia es de 2 a 4 por 1.000 nacidos vivos. En Estados Unidos, Inglaterra y los países escandinavos la incidencia es sensiblemente alta. Por el contrario, los casos publicados en Latinoamérica, Asia, Africa y el Sur de Europa son bastante raros o muy excepcionales (10).

Hasta el momento no existe una evidencia clara que la enfermedad esté presente al nacer, por lo tanto el término congénito es bastante relativo. Para que la EHP se presente clínicamente es necesario un período de vida extra-uterina de tres semanas.

EI conjunto de todos estos fenómenos clínicos y estadísticos llevan a los médicos genetistas a

TAB L A No 3

GRUPOS RACIALES Y EHP. EN HAWAII (*)

\begin{tabular}{lrrll}
\hline Raza & $\begin{array}{c}\text { Nacimien- } \\
\text { tos }\end{array}$ & EHP & Casos & $\begin{array}{c}\text { por 1.000 } \\
\text { nacidos vivos }\end{array}$ \\
\hline Bjancos & 83.257 & 157 & 1,9 & $(1: 530)$ \\
Puerto Rico & 3.850 & 4 & 1,0 & $(1: 1.000)$ \\
Japoneses & 73.831 & 43 & 0,53 & $(1: 1.920)$ \\
Filipinos & 22.630 & 2 & 0,09 & $(1: 11.000)$ \\
Chinos & 11.274 & 0 & 0,0 & 0 \\
\hline
\end{tabular}

(*) Original de Walton K, T. Shim.

T A. B A Ne 4

INCIDENCIA DE LA EHP EN DIFERENTES PAISES ( $\left.{ }^{*}\right)$

\begin{tabular}{|c|c|c|}
\hline Paises & Alio & $\begin{array}{c}\text { Casos por t.000 } \\
\text { nacidos vivos }\end{array}$ \\
\hline Inglaterra & 1951 & 2,9 \\
\hline Israel & 1963 & 0,5 \\
\hline Malasia & 1951 & 0,0 \\
\hline Escocia & $1951-56$ & 2,4 \\
\hline Suecia & 1941.60 & 3,0 \\
\hline Turquía & 1940 & 0,0 \\
\hline U.S.A. & 1957 & \\
\hline Blancos & & 1,6 \\
\hline Negros & & 8,5 \\
\hline
\end{tabular}

(*) Original de Manton K. T. Shim. 


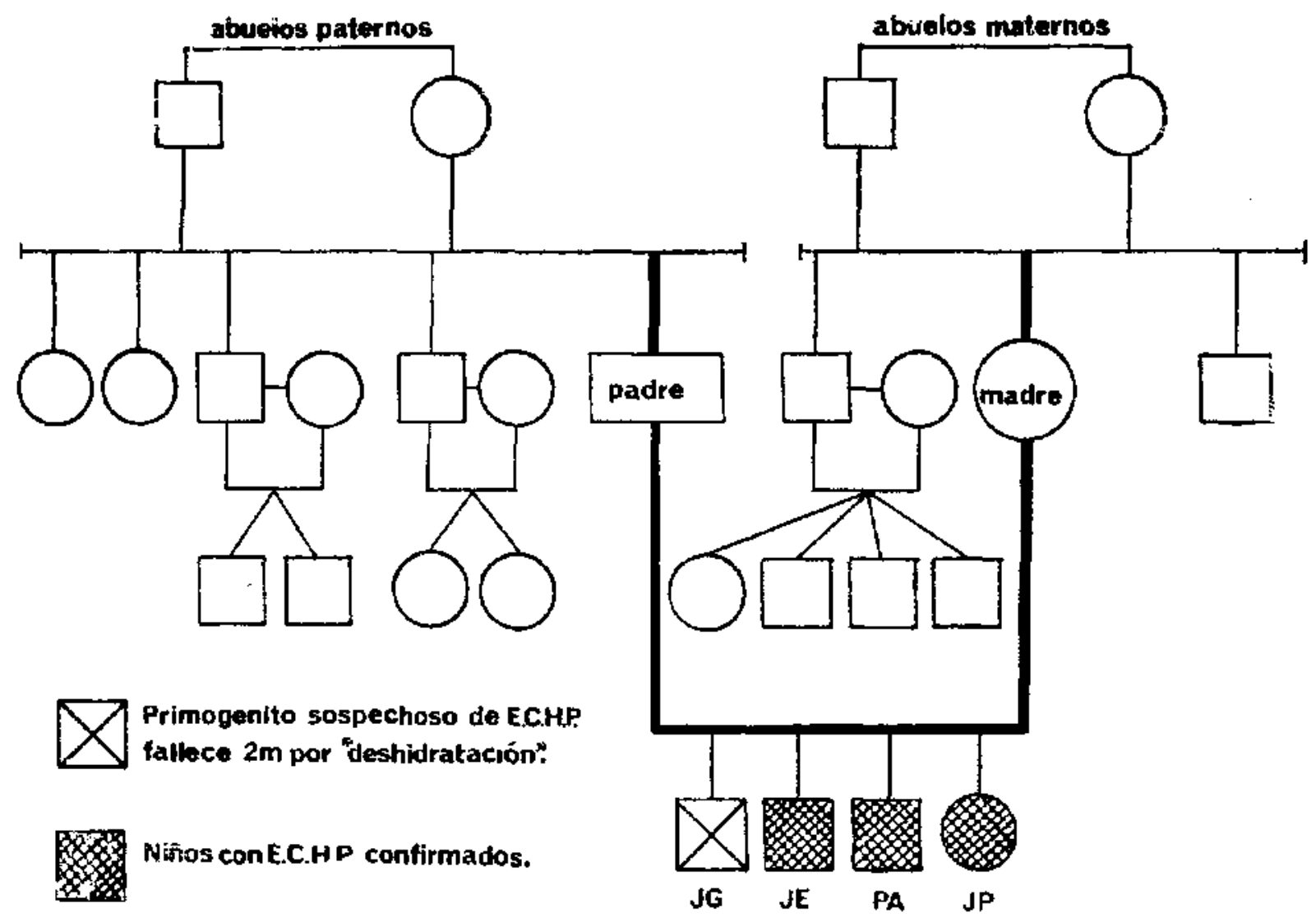

Figura Nu 1

plantearse que el fenóneno denominado EHP es la resultante de factores ambientales y genéticos que se relacionan y se influyen reciprocamente entre sí (1), (4). Bilodeau (1) ha esquematizado los siguientes puntos a favor de la influencia ambiental:

a) La incidencia de la EHP es mayor en ef primer hijo que en los otros.

b) El comienzo de los síntomas es más tardío en los niños alimentados en horarios de cuatro horas que en los de tres horas.

c) El vómito es más tardío en aquellos que nacen en los hospitales que en los nacidos en sus domicilios.

d) Se sabe que un $40 \%$ de los gemelos homozigotos son discordantes, es decir, que en gemelos idénticos en los cuales uno padece de la EHP el otro es sano en el $40 \%$ de los casos, dado que los homozigotos ticnen cl mismo modelo genético se supone que esta altil diferencia sc debe a la influencia ambiental sobre la cualidad genética específica. Por otro lado, el propio Bilodeau analiza y recalca aquellos factores genéticos más relevantes que se manifiestan por: a) La snorme predominancia del sexo mas. culino.

b) Hay un gran número de casos publicados en que uno de los progenitores de los niños con EHP han tenido esta afección en su infancia.

c) Los parientes inmediatos de los casos sintomáticos tienen un alto riesgo de presentar la enfermedad en relación à la población general.

d) La incidencia de la EHP en los gemelos es diez veces más alta que en la población normal.

e) En las mujeres es poco frecuente la EHP. Sin embargo, el riesgo que sus propios hijos tengan la enfermedad es cuatro veces más alta que en los hijos de hombres que han tenido la EHP. Los serios estudios de Carter y colaboradores (4), respecto a la herencia de la EHP indican que esta afección es transmitida por un gene dominante y que se expresa clínicamente al ser influenciado por ei sexo del individuo y por el número de genes que tiene en su estructura genética. Es el propio Carter que da el ejemplo teórico: un niño con 10 genes puede ser asintomátíco, pero sí tuviera 11 , tendrá expresión clínica. Lo mismo sucede con la mujer, pero siendo en ellas necesario un nú- 
mero mayor de genes EHP para que exista Ja enfermedad. Denomina "umbral límite" a este número crítico de gencs que tienen que ser sobrepasados para que la EHP tenga una evidencia sintomática.

En resumen, los más recientes estudios genéticos sostienen la hipótesis que la enfermedad EHP es heredada por un rasgo dominante poligénico y que el umbral limite de estos genes para expresarse clínicamente es más bajo en los hombres que en las mujeres. Las mujeres afectadas de EHP tienen un mayor número de genes EHP portadores que un varón afectado de la EHP, por lo cual el riesgo de los hijos de madres EHP cs bastante más alto que los hijos de padres EHP.

En nuestros casos, el cuadro clínico de los tres hermanos $\mathbf{P}$. R., es el clásico en cuanto a la aparición y características de los vómitos, que es el signo cardinal (6). Aparecen desde la segunda semana de la vida en forma progresiva. Se asocian a una baja de peso, ondas peristálticas gástricas visibles, masa pilórica palpable, deshidratación leve y signología radiológica típica (12). El pre-operatorio es primordial en cuanto a una correcta terapia parenteral realizada con calma (5) dado que la EHP no es una emergencia quirúrgica (10). En nuestros casos no hubo un trastorno metabólico agudo, sea hídrico o electrolítico, clínicamente evidente, (2), debido en parte a que el diagnóstico fue relativamente precoz. La piloromiotomía de $C$. Randstedt, que tiene más de sesenta años de aplicación, fue realizada por grupos diferentes de cirujano de nuestro Hospital constatándose en los tres casos el tumor pilórico. No hubo complicaciones post-operatorias inmediatas y la mortalidad fue nula.

En este grupo de niños no hay antecedentes de la enfermedad en las líneas paternas y maternas después de efectuar una investigación dirigida. (Figura No 1). El primer bijo, varón de $3.100 \mathrm{gr}$. y parto normal, nacido en 1967 , falleció a los dos meses de edad por un cuadro de deshidratación por vómitos y "diarrea". Aunque la enfermedad diarreica aguda es una de las primeras causas de muerte en Chile (13), es tentadora la jdea que también pudiera tratarse de una hipotética EHP no diagnosticada. El matrimonio es joven, pues el padre actualmente tiene 27 años $y$ la madre cumplió 21 años.

En los casos publicados en nuestro país (7) (8), no aparecen casos de hermanos o parientes claramente definidos.

\section{RESUMEN}

Se relata el caso de una familia con cuatro hijos de los cuales los tres últimos consecutivamente tienen EHP. Se sintetizan los factores genéticos relacionalos. Se trataria del primer caso publicado en Chile.

\section{SUMMARY}

A family is reported in which 3 of her 4 children have hypertrophic pyloric stenosis. Inheritance facts are briefly discussed.

\section{BibLJOGRAFía}

1.-- Bilodertt. R. G. Inheritınce of H. P. S. Radiology, 113, No 2, pp. 241-244.

2.-- Britsilow. S. W. Tratamiento parenteral de vónitos y diarrea. Clin. Ped. N. A., Nov. 1964; pp. 889890.

3.-Cameron, A. L. Finmilial Oeurrence of Congenitil H. P. S. A. M. A. Arch. Surg. 1955. 70 pp. $877-894$

4.-Corter. C. O. Inheritance of H. P. S. Brit. Med. Bul1., 1960-1961, 16-17, pp. 251-253.

5. Gillis, and Kagan. Current. Ped Therapy. 3. W. B. Satunders, 1968, pp. 295-297.

6.- Hasban, Jalio. Vómitor en el niño, Pediatría (Santiago) 1960,3 , pp. 169-184.

7.- Jeria, H. y Morento, A. Estenosis hipertrófica del píloro, Rev. Chil. Ped., 1966, 37 np. 765-771.

8.- Molo, A. y Urizola. A. Estenosis hipertrófica del píloro, Rev. Chil. Ped., 1956, 27, pp. 179.

9. - Mencehtelo, Jubie. Pediatría. Intermédica Bs. As. 1972, pp. 274-275.

10.-- Ralfensperger, J. T. Abelomen agudo en latctanles y niños, Ed. Bernado S. A. Bs. As. 1972, pp. 72-80.

11.- Sthm. Watter. K. T. Pyloric steno is in the racciat sroup of Hawaii, J. of Ped. 76, 1, pp. 89-93.

12.-Shumal, F. l. The Radiographic Diagnosis of Congenital H. P. S. J. of Ped. 71, 1, pp. 7(1-74.

13.- Normas de Atención de Enfermedades Respiratorias y Digestivils. Dirección Genera1 del Servicio. Nacional de Salud, Sántiago Chile, 1972. 